\title{
Una Investigación Histórica sobre la Formación del Bloque Hegemónico de los Estados Unidos en las Américas
}

\author{
A historical Research on the Formation of U.S. Hegemonic Bloc in the
} Americas

Elaheh Nourigholamizadeh

Universidad de Teherán, Irán

\section{RESUMEN}

Desde la Doctrina Monroe (1823) hasta el final de la Segunda Guerra Mundial, los Estados Unidos tomó gradualmente el lugar de las potencias colonialistas europeas en América Latina y empleó una amplia gama de los compromisos políticos en los países de región que le brindaron una potencia dominante en el hemisferio occidental. Durante la Guerra Fría, las políticas intervencionistas de los EE.UU. en los asuntos domésticos de los países latinoamericanos establecieron la "hegemonía estadounidense en América Latina". Una investigación histórica sobre las relaciones de los países americanos muestra que según la perspectiva neo-Gramsciana, la hegemonía liberal de los EE.UU. en América Latina es preservada y promovida por tres pilares: cultura liberal; organizaciones interamericanas; y capacidades militares y económicas. Estos tres pilares también se han extendido a otras partes del mundo.

PALABRAS CLAVE: Bloque hegemónico de los Estados Unidos; América Latina; Investigación histórica; Perspectiva neo-Gramsciana

\section{ABSTRACT}

From the Monroe Doctrine (1823) to the end of World War II, the United States gradually took the place of the European colonial powers in Latin America and 
employed a wide range of political engagements in the countries of the region that gave it a dominant power in the Western Hemisphere. During the Cold War, US interventionist policies in the domestic affairs of the Latin American countries established the "American hegemony in Latin America". A historical research on the U.S-Latin America relations shows that according to the neoGramscian perspective, US liberal hegemony in Latin America is preserved and promoted by three pillars: liberal culture; inter-American organizations; and US military and economic capabilities. These three pillars have also spread to other parts of the world.

KEY WORDS: United States of America, Latin America, Historical Research, Neo-Gramscian Perspective, U.S. Hegemonic Bloc

\section{INTRODUCCIÓN ${ }^{1}$}

Históricamente, la relación entre los Estados Unidos e América Latina tiene sus raíces en las primeras décadas de la independencia de los EE.UU. Desde la Doctrina Monroe (1823) hasta el final de la Segunda Guerra Mundial, los Estados Unidos tomó gradualmente el lugar de las potencias colonialistas europeas en América Latina y empleó una amplia gama de compromisos políticos en los países de esta región que le brindaron una posición dominante en el hemisferio occidental. Del mismo modo, durante la Guerra Fría, a pesar de su rivalidad contra la Unión Soviética en diferentes regiones del mundo inclusivo América Latina, los Estados Unidos mantuvo su posición dominante en las Américas. Resultado de esta situación fue la "hegemonía estadounidense en América Latina" que se estableció después del colapso de URSS en 1991. En otras palabras, las relaciones de poder en el continente Americano han sido siempre definidas por las políticas hegemonistas de los Estados Unidos hacia sus vecinos latinoamericanos.

La hegemonía, por lo general, se refiere a la supremacía que un estado ejerce sobre otros estados. En este sentido el proceso de la formación de una hegemonía es un factor substancial para definir las evoluciones del poder en la arena internacional. Dado la posición dominante del los Estados Unidos en las Américas, la pregunta fundamental es como emergió la hegemonía

1 Este artículo es derivado de la disertación titulada "US Leadership in Latin America's Leading Economies during Barack Obama's Administration (2009-2017)”, Facultad de Estudios del Mundo, Universidad de Teherán, Irán. 
estadounidense en el continente Americano. Entonces esta investigación se dedica a ofrecer una investigación histórica sobre el proceso de la formación de hegemonía estadounidense en América Latina. Claramente, las teorías críticas de hegemonía pueden presentar las explicaciones iluminadores de las evoluciones históricas. Por lo tanto, las partes siguientes inicialmente introducen una explicación neo-Gramsciana del proceso de la formación de bloque hegemónico de los Estados Unidos y después ofrecen una investigación histórica de la formación de ese bloque en América Latina.

\section{EXPLICACIÓN DEL BLOQUE HEGEMÓNICO DE LOS ESTADOS UNIDOS}

En la disciplina de las Relaciones Internacionales, hay diferentes perspectivas para explicar la hegemonía. Pero una visión crítica que se dedica principalmente al análisis del proceso de surgimiento de un fenómeno hegemónico es aquella de Antonio Gramsci. Antonio Gramsci sostiene que la hegemonía se refiere al éxito de las clases dominantes al presentar su significado de realidad de manera que otras clases lo reconocen como "sentido común" (Senso comune). Gramsci concentra en una dicotomía tradicional entre "coerción y consenso" que caracteriza el pensamiento político italiano de Maquiavelo a Pareto. Él cree que la supremacía de un grupo o una clase social se presenta de dos maneras diferentes: a) dominación (dominio) o coerción, b) liderazgo intelectual y moral (direzione intellettuale e morale) (Gramsci 1949c: 70). Es decir, el control social afecta al comportamiento y pensamiento de los individuos por dos formas principales: a) externamente a través de dar recompensas e imponer castigos, $b$ ) internamente a través de moldear las convicciones personales como normas prevalecientes. En este sentido, el "control externo" se basa en el uso de la fuerza y coerción y el "control interno" se apoya en la hegemonía como un orden que se presenta en forma de un lenguaje social-moral común y un concepto dominante de realidad que incluye todos los modos del pensamiento y comportamiento. Este predominio se obtiene mediante el consenso en lugar de la coerción de una clase sobre otras clases. En consecuencia, aunque la "dominación" se realiza mediante el mecanismo coercitivo de estado o "sociedad política", "liderazgo intelectual y moral" se obtiene y se ejerce principalmente a través de la "sociedad civil" que es el conjunto de las instituciones educativas, religiosas y asociativas (Gramsci 1949: 87, 130, 133, 150). Así, la hegemonía se implementa de diversas maneras en las que varias instituciones de la sociedad civil moldean directa o indirectamente las estructuras cognitivas y afectivas utilizadas para percibir y evaluar la realidad social problemática. En este sentido, Gramsci usa la metáfora del centauro de Maquiavelo para caracterizar el poder; 
el poder es como un centauro, mitad humano y mitad animal, siempre es de dos estratos y incluye el uso de la fuerza y la coerción por un lado, y el consenso y la hegemonía por el otro (Gramsci 1949b: 1951). Además, la supremacía ideológica tiene sus raíces en los asuntos económicos: "si la hegemonía es ético-política, también debe ser económica, también debe tener su fundamento en la función decisiva que ejerce el grupo dirigente en el núcleo decisivo de la actividad económica" (Gramsci 1949b: 32, 39). Entonces, el capitalismo mantiene el control no solo a través de la fuerza, violencia y coerción política y económica, sino también a través de la ideología. En el entretanto, la burguesía avanza una cultura hegemónica que difunde sus propios valores y normas para convertirlos en el valor común de todos.

Por lo tanto, la hegemonía es la forma más elevada de dominación. Efectivamente, la dominación se refiere a la coerción ejercida por la sociedad política o el estado, mientras que la hegemonía es el momento de consenso y liderazgo cultural obtenido por la sociedad civil (Fontana 2008). En esta situación, los grupos sociales subalternos que no tienen suficiente autonomía política pueden adaptarse a los actos e intereses promovidos por las élites (Howson \& Smith 2008). Entonces el estado ejerce su poder para preservar estos intereses manteniendo a los grupos subordinados pasivos y fragmentados. Esta persuasión (consenso) es ejecutada por los intelectuales, quienes forman los agentes de conexión entre la sociedad política y la sociedad civil (Gramsci 1949a). En consecuencia, la hegemonía se entiende en términos de liderazgo político, económico, ideológico y cultural.

Gramsci destaca que no hay una sola clase dominante, sino una alianza inestable y cambiante de diferentes clases sociales. Así, la idea de una ideología dominante se sustituye por la idea de un conjunto de discursos dominantes que son inestables, temporales y transitorios. Según Gramsci, por un lado están las clases dominantes que incorporan todos los pensamientos y comportamientos dentro de los límites de sus intereses (conocido como hegemonía) y por otro lado las clases dominadas (subordinadas) que intentan mantener y avanzar sus propios valores y normas (conocido como contra-hegemonía). El resultado es la lucha permanente por el dominio entre las ideologías de las clases dominantes y las de otros grupos en la sociedad (Gramsci 1949a, 1949c). En breve, la cultura se define como el producto de una lucha incesante entre diversas fuerzas de la sociedad y la hegemonía se define como liderazgo político, económico, ideológico y cultural que es resultado de un juego complicado de negociaciones, debates, alineaciones, desalineaciones y realineamientos dentro de la sociedad. 
Gramsci, como un conocido teórico marxista, presta algunos elementos de los argumentos y supuestos marxistas, por ejemplo, la lucha de clases y la base/superestructura. Para Gramsci, la hegemonía como liderazgo intelectual y moral se realiza mediante las alianzas y los compromisos de una variedad de fuerzas sociales. Esta unión de fuerzas sociales crea un "bloque histórico" que es la base del consenso. Este consenso a su vez conduce a un orden social particular que produce y reproduce la hegemonía de la clase dominante a través de diversas instituciones educativas, religiosas y asociativas. En consecuencia, el "bloque histórico" de Gramsci se refiere a la realización o concretización de la relación entre los proyectos hegemónicos y la reproducción estructural que él ve en términos de la unidad entre estructura y superestructura (Joseph 2002: 31).

Entonces, la formación de la hegemonía a nivel de grupos sociales es estrechamente relacionada con la formación de la sociedad en el nivel político (o el nivel de producción). Es decir, un grupo requiere tanto las condiciones económicas como las condiciones políticas y culturales para convertirse en un fenómeno hegemónico, o para preservar su posición dirigente o hegemónica. En este sentido, un bloque hegemónico gobernante debe preservarse a través de organizar y reorganizar los grupos sociales y las relaciones sociales de acuerdo con sus desarrollos en la sociedad.

El desarrollo de un bloque hegemónico viene por cierto perturbado por la lucha de la clase trabajadora para lograr la hegemonía dentro de una sociedad. Esta lucha de clases que deriva de la resistencia de la clase dominada (o ideología dominada) contra la explotación cultural, ideológica, política y económica de la clase dominante es de alguna manera incrustada en las relaciones sociales de producción y en situaciones severas puede conducir a las luchas revolucionarias. Como expresado por Paul Ransome (1992):

La clave del cambio social "revolucionario" en las sociedades modernas no depende, como lo predijo Marx, del despierto espontáneo de la conciencia de clase crítica, sino de la formación previa de nuevas alianzas de intereses, una hegemonía alternativa o un "bloque histórico" alternativo, que ya ha desarrollado una visión cohesiva del mundo (Ransome 1992: 27).

Aunque discutir los orígenes marxistas de la concepción gramsciana de la hegemonía requiere más aclaraciones, las explicaciones mencionadas parecen suficientes para el propósito de esta investigación. En resumen, según Gramsci, la hegemonía es la combinación de coerción y consenso, es decir, "el trabajo 
junto de la sociedad política con la sociedad civil; de la libertad con la restricción; de la superestructura con la estructura -siempre bajo un nuevo liderazgo moral e intelectual" (Howson \& Smith 2008). Por lo tanto, los estados que son hegemónicos pueden tener una influencia extraordinaria en muchos otros países a través de la fuerza militar o el control de las industrias comerciales. Estados Unidos de América, como el país más influyente del mundo desde 1945, posee todas las características de un hegemón descrito por este enfoque crítico. Sin embargo, explicar su posición hegemónica requiere una nueva versión de la teoría crítica de Gramsci, que es la teoría neo-Gramsciana.

La teoría neo-Gramsciana fue acuñada a principios de los 80 por Robert Cox en dos artículos fundamentales: Fuerzas Sociales, Estados, y Órdenes Mundiales: Más allá de la Teoría de las Relaciones Internacionales (1981) y Gramsci, Hegemonía y Relaciones Internacionales: Un Ensayo sobre el Método (1983). La teoría se centra en la construcción de la hegemonía que comienza con las fuerzas sociales que desempeñan un papel crucial dentro de un estado y luego se extienden hacia afuera al nivel mundial. En este sentido, la hegemonía se define como una manifestación de un amplio consenso expresado por el reconocimiento de las ideas y reforzado por las instituciones y los recursos materiales. En contraste con los enfoques positivistas y pos-positivistas de las Relaciones Internacionales que ofrecen una teoría radical y estática de la política, el estado y el orden mundial, Cox no toma por entendido las instituciones y las relaciones de poder, sino que las cuestiona a través de explorar su orígenes y sus evoluciones (Cox 1981: 129). Cox analiza el surgimiento de los órdenes mundiales existentes y el establecimiento de las normas, instituciones y prácticas dominantes. Este análisis ofrece la base para identificar aquellas fuerzas que conducen a un orden mundial nuevo y más justo.

Es decir, el enfoque neorrealista argumenta que los estados son los únicos actores importantes en la arena internacional, el enfoque institucionalista neoliberal considera los estados como los actores más importantes que usan regímenes para desarrollar sus intereses, y la teoría de sistemas mundiales divide el sistema mundial en el centro, la semi-periferia, la periferia y la arena exterior. Obviamente, todas estas teorías suponen que las características fundamentales del sistema internacional son constantes. Por al contrario, el enfoque neoGramsciano desarrollado por Cox amplía el dominio de la hegemonía de lo que fue explicado por la Teoría de la Estabilidad Hegemónica (TEH). La TEH sostiene que "una distribución hegemónica del poder, definida como aquella en la cual un solo estado tiene un predominio del poder, es la más propicia para el 
establecimiento de un sistema económico internacional estable y abierto" (Webb \& Krasner 1989: 183), pero Cox cree que el surgimiento de una situación hegemónica dentro de un orden mundial "se basa en una conjunción coherente o ... una configuración del poder material, en la imagen colectiva prevaleciente del orden mundial (incluidas ciertas normas) y en una serie de instituciones que administran el orden con una cierta apariencia de universalidad". En este sentido, "la dominación de un estado poderoso puede ser una condición necesaria pero no suficiente de hegemonía” (Cox 1981: 139).

En la teoría crítica de Cox, la hegemonía dentro de una estructura histórica se constituye en tres esferas de actividad: las "Relaciones sociales de producción" que abarcan la totalidad de las relaciones sociales en formas materiales, institucionales y discursivas que producen fuerzas sociales particulares; "Formas de estado" que incluyen complejos históricamente contingentes de la sociedad civil-estatal; y "Órdenes mundiales" que no solo muestran las fases de estabilidad y conflicto, sino también explican cómo podrían surgir las formas alternativas del orden mundial (Cox 1981: 135-138). La siguiente figura representa la interacción entre estas fases:

Figura 1. La relación dialéctica de las fuerzas

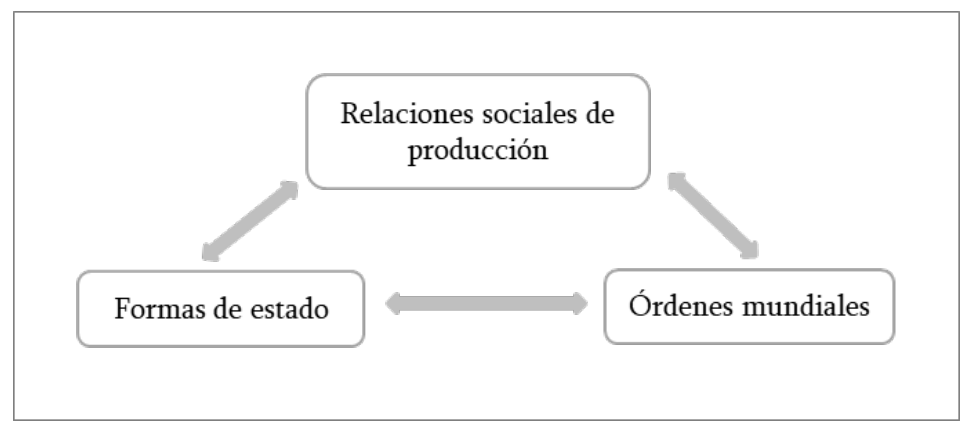

Fuente: (Bieler \& Morton 2004: 88).

Por lo tanto, la teoría neo-Gramsciana enfatiza la interacción entre procesos particulares, especialmente aquellos originados de las posibilidades dialécticas de cambio dentro de la esfera de la producción y el carácter explotador de las relaciones sociales que no se consideran como esencias ahistóricas inmutables sino como una creación continua de nuevas formas y nuevos órdenes (Cox 1981: 132). Para explicar más: 
Las "relaciones sociales de producción" en la teoría de Cox sirven como punto de partida para analizar la operación y los mecanismos de la hegemonía. La producción se considera en un sentido amplio e incluye la producción y reproducción del conocimiento, las relaciones sociales, la moralidad y las instituciones que son condiciones previas para la producción de bienes físicos. Estos procesos se consideran como los modos de las relaciones sociales de producción que producen fuerzas sociales como los actores colectivos más importantes. En este sentido, los diferentes modos de las relaciones sociales de producción engendran las relaciones de producción cambiantes que dan lugar a fuerzas sociales particulares que forman las bases del poder dentro y entre estados y dentro de un orden mundial específico. Además, esta concepción de la producción comprende no solo los aspectos materiales, sino también los asuntos "no clasistas" como la paz, la ecología y el feminismo (Cox 1987).

Las "formas de estado" constituyen la segunda esfera de actividad. El poder del estado se basa en las formaciones subyacentes de las fuerzas sociales. Por lo tanto, el estado no es una categoría institucional dada o pre-constituida, sino que es relacionada con la construcción histórica de varias formas de estado y el contexto social de la lucha política. Efectivamente, el concepto de un bloque histórico y las relaciones dentro de la sociedad civil son involucrados en la creación de una forma de estado. Es decir, un bloque histórico se refiere al establecimiento de una relación por fuerzas sociales líderes dentro de un contexto nacional específico. Este proceso va más allá de una alianza política entre fuerzas sociales representadas por las clases o las fracciones de clases e implica la integración de una variedad de diferentes intereses de clase que proliferan en toda la sociedad. El resultado es la unión de los objetivos económicos y políticos y la unidad intelectual y moral en un nivel universal. Por lo tanto, las diferentes formas de estado se consideran como la manifestación de los bloques históricos particulares. Obviamente, este procedimiento proviene de Gramsci que define el estado no solo como el aparato de gobierno que opera dentro de la esfera "pública" (gobierno, partidos políticos, militares) sino también como parte de la esfera "privada" de la sociedad civil (iglesia, medios de comunicación, educación) a través de la cual funciona la hegemonía. En general, se puede argumentar que el estado no es una categoría institucional distinta, sino una forma de las relaciones sociales a través de la cual se expresan el capitalismo y la hegemonía (Bieler \& Morton 2004). 
En tercer lugar, el "orden mundial" no solo se refiere a las fases de estabilidad y conflicto, sino que también apunta al surgimiento de las formas alternativas del orden mundial (Cox 1981: 135-138). La construcción de un bloque histórico depende de una clase social hegemónica que crea un fenómeno nacional. La consolidación de una hegemonía a nivel doméstico da lugar a un orden social particular que se mueve hacia afuera al nivel mundial a través de la expansión internacional de un modo particular de las relaciones sociales de producción (Cox 1983, 1987). Esta forma del orden mundial hegemónico se apoya en las instituciones y organizaciones internacionales.

Además, cada una de estas tres esferas incluye elementos que se combinan recíprocamente para constituir una estructura histórica: "ideas" que se refieren a los significados intersubjetivos así como a las imágenes colectivas del orden mundial; "Capacidades materiales" que se consideran como los recursos acumulados; y las "instituciones" que son amalgamas de los dos elementos anteriores y son medios para estabilizar un orden particular (Cox 1981: 136). La siguiente figura representa estos elementos:

Figura 2. El momento dialéctico de la hegemonía

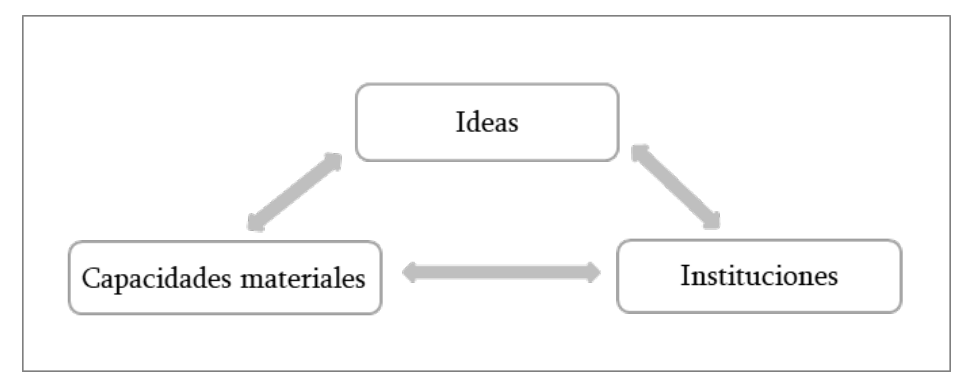

Fuente: (Bieler \& Morton 2004: 88)

En consecuencia, el objetivo del enfoque neo-Gramsciano es analizar e identificar estructuras históricas coherentes -incluyendo diferentes patrones de las relaciones sociales de producción, las formas de estado y el orden mundialque han existido dentro del modo de producción capitalista durante diferentes períodos de tiempo. Efectivamente, las relaciones sociales de producción engendran fuerzas sociales que se consideran los principales actores colectivos. Estas fuerzas sociales operan dentro de todas las esferas de actividad y el aumento de las fuerzas sociales contendientes y rivales conduce a cambios en la 
producción que a su vez produce cambios en las formas de estado y el orden mundial (Cox 1987). Entonces el enfoque neo-gramsciano ofrece un buen instrumento para explicar el proceso de surgimiento del bloque hegemónico de los Estados Unidos.

Después de la Segunda Guerra Mundial, los Estados Unidos de América se convirtió en el poder dominante del mundo. A pesar de su posición superior, EE.UU. enfrentó desafíos que amenazaron su dominación. En otras palabras, Keohane argumentó que después de mediados de la década de 1960, la recuperación económica y la creciente unidad de Europa y el rápido crecimiento económico de Japón desafiaron el dominio de los EE.UU. en la economía política mundial. No obstante, la interdependencia económica continuó creciendo, y el ritmo de la mayor participación de los Estados Unidos en la economía mundial se aceleró después de 1970 (Keohane 1984). Esto significa que Estados Unidos conservó su posición hegemónica en el mundo incluso después del surgimiento de problemas desafiantes durante los años sesenta y setenta. Además, Joseph Nye presentó los Estados Unidos como el estado líder del siglo XX y del siglo XXI, respectivamente, basándose en la situación económica, el liderazgo científico y técnico, la ubicación, las fuerzas y alianzas militares, la cultura universalista, los regímenes internacionales liberales, la capacidad militar, el poder blando y el centro de comunicación transnacional (Nye 2002: 555). Estos factores fueron etiquetados como liberalismo.

Según la perspectiva neo-Gramsciana, se puede argumentar que los Estados Unidos usó el liberalismo como una herramienta para formar su hegemonía global, porque el liberalismo se basa en el consenso y por ende es legitimador. Esta situación se refleja en el triángulo de paz de Immanuel Kant que incluye la democracia, las organizaciones internacionales y la interdependencia económica (Kant 1970). El triángulo kantiano corresponde también al momento dialéctico de hegemonía de Cox y muestra que los Estados Unidos de América ha construido su bloque hegemónico basándose en los valores liberales que también se consideran como una medida para mantener su hegemonía liberal. Por lo tanto, no es necesario utilizar la coerción ya que el liberalismo se refuerza, se legitima y se perpetúa a sí mismo. El liberalismo también disuelve las ideas contra-hegemónicas en la amalgama de sus organizaciones internacionales, la interdependencia económica y la democracia.

Las organizaciones o instituciones internacionales incluyen las instituciones de Bretton Woods (el Banco Mundial (BM) y el Fondo Monetario Internacional (FMI)), la Organización Mundial del Comercio (OMC) y las Naciones Unidas 
(ONU), la Unión Europea (UE), Organización del Tratado del Atlántico Norte (OTAN), etc. Por supuesto, las organizaciones internacionales no se limitan a estas instituciones $\mathrm{y}$, como argumenta Cox, consisten en cinco normas universales de la hegemonía (Cox, 1983, p. 62):

1. Incorporan las reglas que facilitan la expansión de los órdenes mundiales hegemónicos;

2. Son el producto del orden mundial hegemónico;

3. Ideológicamente legitiman las normas del orden mundial;

4. Eligen a las élites de los países periféricos; y

5. Disuelven ideas contra-hegemónicas.

Estas normas se han empleado desde la época de la posguerra para mantener la legitimidad hegemónica de los EE. UU. Estas normas facilitan la imposición de la voluntad de hegemón a través los programas institucionales como el Consenso de Washington, los Documentos de Estrategia de Lucha contra la Pobreza (DELP) del FMI, etc. Además, la estructura formal e informal de estas instituciones reafirma la jerarquía hegemónica y permite las modificaciones a favor de los intereses subordinados solo con la precondición de mantener los intereses del hegemón. El sistema de votación de las Naciones Unidas es un ejemplo del papel de las instituciones en la formación y preservación del estado hegemónico. Las instituciones también se legitiman y absorben las ideas y los movimientos contra-hegemónicos. Cox señala que "la hegemonía es como una almohada: absorbe los golpes y tarde o temprano el que lo atacó encontrará que es cómodo descansar sobre él" (Cox 1983: 63). Entonces, resistir contra el orden liberal implica correr el riesgo de ser categorizado junto con los regímenes deshonestos y con los enemigos de la libertad económica y política. Por lo tanto, EE.UU. se concentró en el desarrollo de las organizaciones o instituciones internacionales para establecer los fundamentos de su bloque hegemónico.

La interdependencia económica realizada en forma del comercio internacional es otro ángulo del triángulo hegemónico kantiano. El capitalismo occidental o estadounidense establecido institucionalmente después de la Segunda Guerra Mundial, está estrechamente vinculado con la competencia y el libre comercio. Las potencias occidentales, especialmente los Estados Unidos, usaron la herramienta del liberalismo económico para unirse a otras partes del mundo. Según Deudney e Ikenberry, la expansión del capitalismo estimulada por el libre 
comercio altera gradualmente las preferencias y el carácter de los estados en una dirección liberal y democrática $\mathrm{y}$, en consecuencia, produce un sistema hospitalario más estratégico y político. Ellos creen que la estrategia de apertura económica actúa como un amortiguador contra los bloques regionales, las guerras comerciales, los regímenes anti-liberales y la rivalidad ruinosa que se considera contra-hegemonía (Deudney \& Ikenberry 1999: 192). Por ejemplo, Wade discute que la OMC promueve consignas como "libre comercio y igualdad de condiciones", pero en realidad provee el campo de juego definitivamente a favor de "Occidente", como se puede ver en los acuerdos y las negociaciones sobre la agricultura, los derechos de propiedad intelectual, etc. (Wade 2014). Por lo tanto, el bloque hegemónico de los Estados Unidos se basó en este patrón de la actividad económica internacional que fortaleció las estructuras históricas de la dominación y dependencia. En consecuencia, los diferentes estados del mundo se ven obligados a seguir la ideología liberal de Estados Unidos para obtener el poder económico. Entonces, esta hegemonía estadounidense no se basa en el consenso, sino en una forma de coerción oculta. Además, estas políticas de liberalización no siempre son beneficiosas para todos los países del mundo y, de hecho, tienen efectos desestabilizadores para los países subdesarrollados. México es un ejemplo en el que la participación del BM y el FMI en 1998 fue más destructiva que beneficiosa.

La democracia que es el tercer ángulo del triángulo hegemónico originalmente proviene del Occidente. Las potencias occidentales, especialmente los Estados Unidos de América, se han centrado en la exportación de la democracia a otros estados del mundo. La exportación de la democracia fue muy importante para los Estados Unidos porque legitimó su intervención en otros estados y convirtió Estados Unidos en una hegemonía global. Según Chandler, "la democracia a menudo se presenta como una solución a los problemas de la esfera política más que como un proceso para determinar y dar contenido a la vida buena" (Chandler 2006: 483). Por lo tanto, democracia fue una solución para los problemas de EE.UU. en términos de expandir su poder a otras partes del mundo. Entonces, la democracia fue un instrumento fuerte para formar y preservar la hegemonía estadounidense cubierta con la etiqueta de liberalismo.

En suma, según la perspectiva neo-Gramsciana, los Estados Unidos de América ha construido su bloque hegemónico basándose en los valores liberales que también se consideran como una medida para mantener su hegemonía liberal. La superestructura de esta relación liberal de producción incluye las organizaciones internacionales, la interdependencia económica y la democracia que han creado el orden internacional posterior a 1945 denominado Pax Americana (Paz 
estadounidense). Este orden se refuerza, se legitima y se perpetúa a sí mismo y disuelve las ideas contra-hegemónicas en la amalgama de sus organizaciones internacionales, la interdependencia económica y la democracia (Figura 2.3). Además, los estados que desafían este orden reciben un signo de la interrogación sobre su legitimidad y autoridad como un estado soberano.

Figura 3. El momento dialéctico de la hegemonía de EE. UU.

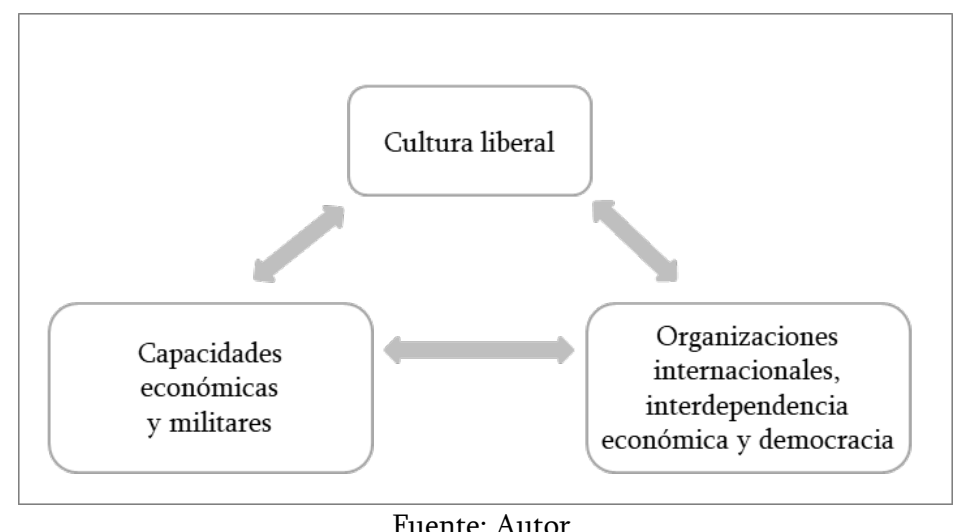

Esta figura muestra cómo se construye y se mantiene el bloque hegemónico de EE.UU. De hecho, el orden hegemónico estadounidense establecido desde 1945 ha obligado a otros estados a involucrarse en las instituciones internacionales, liberalizar sus economías y fortalecer sus democracias. Obviamente, este procedimiento proviene de Gramsci, que considera la hegemonía de los Estados Unidos no solo como el aparato del gobierno estadounidense que opera dentro de la esfera "pública" (gobierno estadounidense, partidos políticos estadounidenses, ejército estadounidense) sino también como parte de la esfera "privada" de la sociedad civil (iglesia, medios de comunicación, educación) a través de la cual funciona la hegemonía. Esto implica que después de la Segunda Guerra Mundial, diferentes fuerzas sociales del mundo como las fuerzas pro-estadounidenses, los movimientos anti-estadounidenses, etc. han operado y luchado dentro de las esferas de actividad para crear un bloque hegemónico estadounidense. Esta parte ofreció una explicación neo-Gramsciana del surgimiento del bloque hegemónico de EE.UU. Dada que la presencia hegemónica estadounidense en América Latina se remonta a las décadas anteriores de la Segunda Guerra Mundial, las partes siguientes explican y analizan la formación del bloque hegemónico de los 
EE.UU. en América Latina, utilizando el método de investigación histórica. De hecho, resumir y reportar los datos de las fuentes primarias y secundarias ofrece una comprensión exhaustiva de las políticas actuales de los EE.UU. hacia los países latinoamericanos.

\section{RELACIONES ENTRE ESTADOS UNIDOS E AMÉRICA LATINA}

América Latina es una región rica e exótica que ha sido siempre involucrada en los juegos de los poderes ambiciosos. Aun el surgimiento del concepto América Latina está enraizado en los objetivos imperialistas y hegemónicos de los poderes occidentales. Michel Gobat en La invención de América Latina: una historia transnacional del antiimperialismo, la democracia y la raza argumenta que el chileno Francisco Bilbao quien utilizó "América Latina” en su discurso en París en 1856 relacionó decisivamente el concepto de América Latina con una alianza continental contra los Estados Unidos y el imperialismo y expansionismo europeo. Esta definición de América Latina fue gradualmente recibida por otras naciones americanas y con el aumento del intervencionismo estadounidense durante el siglo XX se identificó también con la defensa de las razas mixtas del continente americano (Gobat 2013). Por lo tanto, la presencia expansionista e intervencionista de los EE.UU. en América Latina tiene una larga historia. Cabe mencionar que la comprensión de esa historia que estableció los valores liberales en América Latina requiere la investigación histórica de las relaciones entre los Estados Unidos y América Latina.

Stewart Brewer en su libro Borders and Bridges: A History of U.S.-Latin American Relations ofrece un enfoque sintético a las relaciones entre los Estados Unidos y América Latina. Brewer discute que la historia de las relaciones políticas, diplomáticas y económicas entre los Estados Unidos y América Latina es de gran importancia porque con el pasar de tiempo esa relación se vuelve cada vez más dependiente y complicada debido a la integración económica y los cambios tecnológicos. Al explicar las relaciones EE.UU.-América Latina, él destaca que en 1500 ni los Estados Unidos ni los imperios británicos estaban en América del Norte. En aquellos años, Cristóbal Colón quien descubrió el Nuevo Mundo en 1492, estaba preparándose para su cuarto y último viaje a América. El Imperio español estaba organizando sus planes militares y religiosos para ocupar los imperios azteca e inca. Vasco da Gama estaba allanando el terreno para comerciar con las Indias Orientales después de cruzar el Cabo de Buena Esperanza y luego llegar a las Indias en el nombre de la corte de Aragón. Pedro 
Cabral reclamaba el descubrimiento de Brasil bajo la bandera de la Corona portuguesa. Y John Cabot ya había aterrizado en algún lugar cerca de Terranova sin permiso de Inglaterra para ir más allá. Brewer continúa sus explicaciones, argumentando que más tarde en 1600, las colonias españolas establecidas en México y Perú se desarrollaron gradualmente mediante la construcción de las ciudades, la fundación de las universidades y la publicación de los periódicos. A pesar de estos desarrollos coloniales, España sufría sus derrotas contra las potencias europeas. Mientras tanto, la Compañía Británica de las Indias Orientales estaba tratando de facilitar el avance de Gran Bretaña hacia América del Norte donde la colonia de Jamestown se estableció en 1607 como la primera colonia británica en el Nuevo Mundo. Además, el Brasil portugués se ocupaba del comercio con Europa. Brewer agrega que en 1700 mientras las colonias españolas del Nuevo Mundo estaban experimentando las reformas masivas debido a los problemas judiciales en España, las trece colonias británicas norteamericanas habían sido fundadas y el explorador francés La Salle había establecido su colonia de Luisiana en 1699 (Brewer 2006). Generalmente, durante el siglo 18 el Nuevo Mundo se dividió entre las potencias europeas como España, Portugal, Gran Bretaña y Francia.

Brewer señala que en 1800 los Estados Unidos de América se habían independizado de Gran Bretaña y formaban una nación independiente bajo la presidencia de John Adams. Durante el siglo 19 Luisiana fue vendida a los Estados Unidos y la mayoría de los países latinoamericanos obtuvieron su independencia de España (Brewer, 2006). Al mismo tiempo, la base de la hegemonía estadounidense en América Latina fue establecida por la Doctrina Monroe propuesta por el quinto presidente de los EE.UU. James Monroe (18171825). La Doctrina Monroe no solo justificó los deseos expansionistas de los Estados Unidos para ocupar Texas, California y la Cuenca del Caribe, sino también facilitó la realización de sus objetivos intervencionistas para tomar gradualmente el lugar de las potencias coloniales europeas en el Nuevo Mundo. Brewer continúa sus argumentos de la historia de las relaciones EE.UU.-América Latina centrándose en la liberación de Cuba y Puerto Rico del control español, la independencia de Panamá y el Corolario de Roosevelt que establecieron los fundamentos de las intervenciones políticas, económicas y militares de los EE.UU. en los asuntos domésticos de los países latinoamericanos. Se debe tener en cuenta que las políticas estadounidenses durante la primera mitad del siglo 20 se combinaron con la posición creciente de los Estados Unidos en la arena internacional después de la Segunda Guerra Mundial y fortificaron la presencia hegemónica de los EE.UU. en el hemisferio occidental durante la Guerra Fría. En 
otras palabras, Brewer cree que las políticas de los EE.UU. durante el siglo 20 como las políticas económicas después de la Gran Depresión, la política de Buena Vecindad, la Alianza para el Progreso, etc. distanciaron los EE.UU. cada vez más de sus vecinos latinoamericanos (Brewer 2006). Entonces, estas políticas formaron el bloque hegemónico de los Estados Unidos en América Latina y gradualmente se cambiaron a los programas como la Lucha contra la Droga, la promoción de la democracia, el respeto a los derechos humanos, etc.

Joseph Smith en The United States and Latin America: A history of American diplomacy, 1776-2000 explica brevemente las relaciones diplomáticas entre los Estados Unidos y América Latina desde 1776 hasta el final del siglo XX. Smith discute el surgimiento de los Estados Unidos como un poder independiente, enfocándose en los temas como la evolución de la Doctrina Monroe, el Destino Manifiesto y expansionismo territorial de los Estados Unidos (1830-79), el Panamericanismo (1879-1900), la Diplomacia del Dólar (1900-28), la política de Buena Vecindad (1928-45) y las política implementadas durante la Guerra Fría (1945-74). Esta narración histórica también destaca otros asuntos como la reciprocidad comercial, los lazos económicos y la diplomacia comercial que realizaron las ambiciones económicas de los EE.UU. en América Latina. Smith indica que los Estados Unidos siempre ha buscado una posición dominante en sus relaciones con los países latinoamericanos. Smith también señala que los temas actuales como la crisis de la deuda, el tratado de libre comercio (TLC), el control de narcóticos, la democracia y los derechos humanos, la migración, etc. facilitan el mantenimiento de esa posición dominante (Smith 2005). De hecho, la obra de Smith ofrece una narración descriptiva de las relaciones políticas de los Estados Unidos con América Latina que su examen crítico puede revelar la naturaleza hegemónica de las políticas estadounidenses hacia América Latina.

Esta naturaleza se revela también por Joseph S. Tulchin en su libro Latin America in International Politics: Challenging US Hegemony. Tulchin va más allá de la narración descriptiva de las relaciones EE.UU.-América Latina, reflejando no solo la visión de los Estados Unidos sino también la de América Latina. Tulchin cree que desde el comienzo del siglo XX hasta el final de la Guerra Fría, las relaciones interamericanas se basaron en los enfoques hegemónicos de los Estados Unidos. En otras palabras, la posición superior de los Estados Unidos hizo la expresión de la agencia latinoamericana más difícil y luego el antiamericanismo se convirtió en una forma de proteger América Latina contra los Estados Unidos. En este sentido, la revolución Cubana en 1959 fue la única expresión latinoamericana durante la Guerra Fría. Aun, según Tulchin, hoy el proceso de globalización ha causado algunos desafíos para la posición 
hegemónica de los Estados Unidos en América Latina (Tulchin 2016). Entonces, Tulchin afirma que históricamente los EE.UU. estableció una posición hegemónica en las Américas que restringió los países latinoamericanos a una situación inferior que no puede ser alterado fácilmente.

The Second Century: U.S.-Latin American Relations Since 1889 escrito por Mark T. Gilderhus también se dedica a representar la naturaleza de la hegemonía estadounidense en el hemisferio occidental. Gilderhus discute que las desigualdades del poder, la riqueza y la influencia son la característica constante de las relaciones EE.UU.-América Latina. Según Gilderhus, esta situación parece inalterable, porque los fundamentos de las relaciones entre EE.UU. e América Latina fueron formulados por la política panamericana de James G. Blaine en 1889. Gilderhus sostiene que "la idea del Hemisferio Occidental siempre ha transmitido un mensaje favorable para los intereses de los Estados Unidos" y ha limitado las selecciones de los latinoamericanos a aquellas impuestas por el poder norteamericano (Gilderhus 2000: 246-247).

Por lo tanto, Grace Livingstone en America's Backyard: The United States and Latin America from the Monroe Doctrine to the War on Terror argumenta que los Estados Unidos ha estado ocupado con la intervención en los asuntos de América Latina por más de 180 años. Livingstone señala que sus métodos de la intervención varían desde instalar los dictadores, apoyar los golpes militares, militarizar los ambientes locales, imponer las políticas económicas, fomentar las políticas sociales, etc. Generalmente, los Estados Unidos considera América Latina como su patio trasero o su esfera de influencia e intenta controlar las fuentes latinoamericanas como la tierra, el trabajo, las materias primas y los capitales. Los gobiernos liberales y las élites privilegiadas son sus instrumentos para realizar estos objetivos económicos y geopolíticos. Por lo tanto, la estrategia estadounidense se enfoca en suprimir a los reformadores o revolucionarios que desafían sus procesos ambiciosos. Livingstone cree que Estados Unidos ha condenado a las naciones latinoamericanas a la pobreza y la desigualdad y brinda diferentes ejemplos del enfoque intervencionista de los Estados Unidos hacia su patio trasero. Las llamadas "repúblicas bananeras" como los protectores de los intereses económicos y políticos de los EE.UU. en América Central; la política de Buena Vecindad del presidente Roosevelt y sus dictadores-amigos en Centroamérica; la Alianza para el Progreso del Presidente Kennedy (1961-63) y establecimiento de la Escuela de las Américas; las dictaduras totalitarias del Cono Sur (Argentina, Chile, Paraguay y Uruguay); las intervenciones militares en forma de golpes de estado en América Latina durante Kennedy y Johnson; Plan Colombia del presidente Clinton (1993-2001); Guerra contra el terror de George 
Bush; los acuerdos de libre comercio como el Tratado de Libre Comercio de América del Norte (TLCAN) son los ejemplos representados por Livingstone para explicar cómo los Estados Unidos ha mantenido sus bloque hegemónico en las Américas. En otras palabras, Livingstone discute que el término "patio trasero de América" se refiere a la mentalidad colonial de los Estados Unidos que se ha desarrollado durante los siglos por todas las administraciones estadounidenses. Actualmente esta mentalidad se refleja en las políticas relacionadas con la democracia, la migración, los narcóticos, los derechos humanos, las prescripciones económicas de FMI y BM, las representaciones mediáticas de Hollywood, etc. (Livingstone 2009). Entonces, la narración crítica de Livingstone no solo arroja luz sobre las partes oscuras de la historia descriptiva, sino también indica las repercusiones de la hegemonía norteamericana en América Latina.

$\mathrm{Al}$ explicar esta mentalidad colonial de los Estados Unidos, Thomas F. O'Brien en Making the Americas: The United States and Latin America from the Age of Revolutions to the Era of Globalization sostiene que durante dos siglos, los pueblos de los Estados Unidos y América Latina se han conectado creando una historia común. En ese proceso, los norteamericanos han seguido una misión de transformación porque tienen confianza en su fe cristiana, su economía capitalista y su forma republicana de gobierno y consideran estos elementos un paradigma digno de emulación. De hecho, los norteamericanos han intentado que sus vecinos emulen su propia imagen a través de la coerción y el consenso. Entonces, la misión estadounidense ha adoptado muchas formas a lo largo de dos siglos que formaron y establecieron su posición dominante en las Américas. Claramente, estas políticas norteamericanas como la expansión territorial, el imperialismo civilizador y las misiones de modernización y globalización se fundan en los valores liberales que constituyen la base de la política exterior estadounidense. Además estas políticas liberales no han logrado resolver las desigualdades existentes en América Latina reforzadas por las situaciones sociales, económicas y políticas de la misma América Latina. El resultado de esta misión hegemónica ha sido no solo la dependencia cultural e económica de América Latina a los Estados Unidos, sino también la emergencia de los movimientos nacionalistas, populistas y izquierdistas en los países latinoamericanos (O’Brien 2007). Así, la historia muestra que el proyecto liberal ha convertido el hemisferio occidental a la región favorable para los intereses de hegemón norteamericano. David Slater en Geopolitics and the Post-Colonial: Rethinking North-South Relations prepara un ejemplo económico. Él muestra que los Estados Unidos con sus instituciones como el Fondo Monetario 
Internacional, el Banco Mundial y La Organización Mundial del Comercio ha tratado de liberar el Tercer Mundo de sus necesidades con el objetivo de crear un mundo de "cuasi soberanías" que puedan ser manipuladas políticamente. Entonces, los países del Tercer Mundo, incluso los países latinoamericanos están subdesarrollados solo porque el desarrollo está definido por los estándares neoliberales (Slater 2004: 93). En resumen, los valores liberales crean un orden liberal que forma, mantiene y fortalece la hegemónica de los EE.UU. en América Latina.

$\mathrm{Al}$ explicar la mentalidad colonial estadounidense que forma la base del proyecto liberal de los Estados Unidos en sus vecinos latinoamericanos, Lars Schoultz en Beneath the United States: A History of U.S. Policy towards Latin America narra una historia detallada de la relación EE.UU.-América Latina. Él representa los orígenes del enfoque hegemónico de los EE.UU. hacia los países latinoamericanos en esta frase de John Quincy Adams: "Latinoamericanos son perezosos, sucios, desagradables y pueden compararse con nada más que un paquete de cerdos". Schoultz cree que desde el punto de vista del norte, América Latina es pobre, débil, frágil, floja, incivilizada, no democrática y definitivamente inferior. Él afirma que "la creencia en la inferioridad latinoamericana es el núcleo esencial de la política de los Estados Unidos hacia América Latina" (Schoultz 1998). Entonces, esta mentalidad forma los fundamentos del bloque hegemónico estadounidense que según la perspectiva neo-Gramsciana se refleja en la intervención cultural, militar, económica y política en los asuntos latinoamericanos.

Generalmente, Alan Brinkley en su libro Historia de Estados Unidos: un país en formación sostiene que la Doctrina Monroe se considera como el manifiesto para la creación de una política exterior estadounidense. Aunque la Doctrina Monroe tuvo poco efecto inmediato, pero se manifestó como una expresión del creciente espíritu de nacionalismo existente en los Estados Unidos en la década de 1820 que condujo a la expansión de las fronteras (Brinkley 2011: 214). Siguiendo este enfoque expansionista, algunos años después del Destino Manifiesto se celebró la primera conferencia continental de los Estados Unidos en Washington en 1889, conocida como Panamericanismo. De hecho, el Panamericanismo fue la manifestación de la visión ideológica de los Estados Unidos con respecto a "América para los norteamericanos" (Cerón 2002: 106) y facilitó el establecimiento de la posición hegemónica estadounidense en las Américas bajo una conferencia propuesta por James Blaine. Claramente, las conferencias panamericanas desde el principio intentaron apoyar las ambiciones económicas y políticas de los Estados Unidos. A lo largo de los años las conferencias 
panamericanas condujeron a la formación de las organizaciones institucionales interamericanas como el Tratado Interamericano de Asistencia Recíproca (TIAR) en 1947; la Organización de Estados Americanos (OEA) en 1948; la Escuela de las Américas en 1963; la Cumbre de las Américas en 1994; etc. que formaron y preservaron la posición dominante de los EE.UU. en las Américas. Cabe mencionar que las instituciones interamericanas facilitaron la realización de los objetivos culturales, militares, económicos y políticos de los EE.UU. reflejados en las políticas exteriores como Gran Garrote, Diplomacia del Dólar, Buena Vecindad, Alianza para el Progreso, promoción de la democracia, Lucha contra Droga, etc. Estas organizaciones fueron uno de los principales pilares del bloque hegemónico de los Estados Unidos que según la perspectiva neo-Gramsciana formaron y establecieron los fundamentos de la superioridad de los Estados Unidos en las Américas y realizaron el sueño de James Blaine.

La literatura discutida en esta parte ofreció una investigación histórica de las intervenciones económicas, culturales y políticas de los Estados Unidos en los asuntos domésticos de los países latinoamericanos. El surgimiento de los Estados Unidos como hegemón en las Américas se remonta a los primeros años de la formación de los Estados Unidos. De hecho, las relaciones de los Estados Unidos con América Latina, el llamado tercer mundo, siempre han sido explicadas por la superioridad e intervención norteamericana desde el comienzo del siglo XIX hasta el presente. En otras palabras, los Estados Unidos ha tenido la mayor influencia (cultural, económica, política, etc.) en todos los rincones del mundo, pero América Latina vive esta realidad de una manera mucho más concreta debido a su proximidad geográfica. Según la escuela neo-gramsciana, Estados Unidos ha establecido y mantenido su hegemonía en América Latina a través de la promoción de sus valores liberales que se refuerzan, se legitiman y se perpetúan a si mismo a lo largo de los siglos y disuelven las ideas contrahegemónicas en la amalgama de sus organizaciones internacionales, la interdependencia económica y la democracia. Así, Octavio Paz, poeta y diplomático mexicano, cree que "los norteamericanos siempre están entre nosotros, incluso cuando nos ignoran, volteando su espalda de nosotros. Su sombra cubre el hemisferio completo. Es la sombra de un gigante. Y la idea que tenemos de este gigante es la misma que puede encontrarse en los cuentos de hadas y leyendas; un gran tipo de disposición amable, un poco simple, un inocente que ignora su propia fuerza y a quien podemos hacer tonto la mayor parte del tiempo, pero cuyo aliento nos puede destruir" (Rangel 1981). Entonces, desde la primera reunión continental en el Panamericanismo de 1889 hasta diez prescripciones del Consenso de Washington en 1989 y hasta las actuales sesiones 
de la Cumbre de las Américas, los Estados Unidos siempre ha estado disfrutando de una posición hegemónica en América Latina a través de la coerción y el consenso. La parte siguiente explica esta presencia hegemónica desde el punto de vista neo-gramsciano.

\section{EXPLICACIÓN DEL BLOQUE HEGEMÓNICO DE LOS ESTADOS UNIDOS EN LAS AMÉRICAS}

Las partes anteriores revisaron la historia de las relaciones EE.UU.-América Latina. Esta investigación histórica muestra que a lo largo de los siglos la hegemonía estadounidense ha sido establecida en América Latina mediante las ambiciones e intervenciones de EE.UU. en los asuntos domésticos de los países latinoamericanos. Esta parte adopta un enfoque neo-gramsciano para explicar los tres pilares de la hegemonía estadounidense en las Américas, centrándose en la cultura liberal, las organizaciones liberales y las capacidades militares y económicas de los Estados Unidos.

El surgimiento de los Estados Unidos como hegemón en las Américas se remonta a los primeros años de la formación de los Estados Unidos. Desde el principio, los Estados Unidos consideró sus vecinos latinoamericanos las criaturas pobres, débiles, frágiles, perezosas, incivilizadas, no democráticas y inferiores que deben ser civilizadas. En el siglo XIX, el quinto presidente de los Estados Unidos James Monroe (1817-1825) propuso su conocida Doctrina Monroe, que no solo terminó la influencia europea en las Américas, sino también justificó los deseos estadounidenses para ocupar Texas, California y la Cuenca del Caribe. La Doctrina Monroe fue, de hecho, la base de una mayor intervención de los Estados Unidos en los países latinoamericanos. En otras palabras, durante el siglo XIX hasta los primeros años del siglo XX, Estados Unidos se dedicó a reconocer la independencia de los países latinoamericanos de sus metrópolis europeas y esa fue, de hecho, una política para tomar el lugar de las potencias europeas en la región. El objetivo se realizó en 1889 cuando se celebró en Washington la primera reunión continental de todas las repúblicas americanas conocida como la Unión Panamericana.

El siglo XX comenzó con la Enmienda Platt que liberó Cuba del yugo del dominio español y lo convirtió en un protectorado de los Estados Unidos. Es decir que la enmienda anunció el inicio del dominio de los EE.UU. no solo en las Américas, sino también en el mundo. Durante la primera mitad del siglo XX, Estados Unidos estaba preocupado por su expansionismo militar en Panamá (1903, 1925), Nicaragua (1912-1933), México (1916), la República Dominicana 
(1916-1922), Haití (1915-1934). ), Guatemala (1920), Costa Rica (1921), Honduras (1924-25), El Salvador (1932), Cuba (1933), etc. En ese tiempo, Estados Unidos intentaba establecer la base de su aparato hegemónico en las Américas a través de la coerción. Estos esfuerzos culminaron con la firma del Tratado Interamericano de Asistencia Recíproca (TIAR) en 1947 y la formación de la Organización de Estados Americanos (OEA) en 1948 que reemplazó a la Unión Panamericana. Estos dos organismos institucionales asumieron la responsabilidad de facilitar la aplicación de las políticas económicas, militares y sociales liberales en América Latina a través de la coerción y el consenso y convirtieron América Latina económica y psicológicamente dependiente a los Estados Unidos. La segunda mitad del siglo XX coincidió con el período conocido como la Guerra Fría. Durante el período, Estados Unidos se convirtió en la potencia dominante del mundo y la revolución de Cuba en 1959 lo impulsó a adoptar las políticas más intervencionistas para contener su conocida rival la Unión Soviética en las Américas. Además, el cuerpo institucional de los EE.UU. fortaleció durante la Guerra Fría y las instituciones políticas y económicas con sede en los Estados Unidos como las Naciones Unidas (ONU), la Organización del Tratado del Atlántico Norte (OTAN), el Fondo Monetario Internacional (FMI) y el Banco Mundial (BM) ayudaron las instituciones interamericanas a mantener la superioridad estadounidense en América Latina. En este sentido, durante las décadas de 1960 y 1970, varios golpes de estado fueron apoyados por los militares estadounidenses en los países latinoamericanos. En la década de 1970, las políticas de los Estados Unidos en América Latina parecían experimentar cambios que duraron a lo largo de los años ochenta y noventa. Estos cambios incluyen el avance de la redemocratización, la crisis de la deuda y las reformas liberales bajo las estrategias pro-mercado del Consenso de Washington. Sin embargo, estos nuevos compromisos políticos continuaron el enfoque hegemonista de los EE.UU. En resumen, durante la Guerra Fría, planes políticos como la Alianza para el Progreso del Presidente Kennedy, la Fundación Nacional para la Democracia del Presidente Reagan, la misión democrática del Presidente Bush junto con el Manifiesto Latinoamericano y el Consenso de Washington de CEPAL intentaron preservar la posición dominante de los EE.UU. en su esfera de influencia y mantener las naciones latinoamericanas protectoras de los intereses nacionales e internacionales de América del Norte.

El final de la Guerra Fría tuvo una gran influencia en la política exterior de los EE.UU. El mundo no se dividía en dos bloques económicos, estratégicos o políticos, los Estados Unidos era la única superpotencia del mundo y su orden neoliberal ya estaba establecido en el hemisferio occidental. Entonces, el enfoque 
ambicioso de los Estados Unidos hacia sus vecinos latinoamericanos continuó en las décadas posteriores a la Guerra Fría bajo los planes democráticos y antinarcóticos del Presidente Clinton y la Guerra contra el Terror del Presidente Bush. Por ejemplo, durante la década de 1990, Fox y Salinas de México, Menem de Argentina, Collor y Cardoso de Brasil, y Fujimori de Perú siguieron las reformas democráticas del mercado liberal sugeridas por el Consenso de Washington que afectaron a la región en su conjunto y condujeron al surgimiento de los gobiernos izquierdistas. Aunque el levantamiento de la Marea Rosa en América Latina fue descrito como "pérdida de Washington en Latinoamérica" (Hakim 2006), se debe tener en cuenta que los fundamentos del bloque hegemónico de los EE.UU. en América Latina son tan fuertes que no pueden arruinarse fácilmente. Refiriendo a la escuela neo-Gramsciana, estos fundamentos se reflejan en la interacción de la cultura liberal, las organizaciones liberales y las capacidades militares y económicas de los EE.UU. en las Américas.

Culturalmente, la promoción de la cultura liberal en América Latina se llevó a cabo a través del intercambio cultural y el conglomerado de los medios. En la década de 1930, la radio entró en América Latina bajo las empresas estadounidenses como CBS y NBC, junto con algunas empresas privadas de los Estados Unidos y continuó sus actividades bajo la Oficina del Coordinador de Asuntos Interamericanos (OCIAA) de Rockefeller durante la Guerra Fría. La televisión entró en la década de 1950 y NBC, CBS y ABC iniciaron sus inversiones en las estaciones de televisión latinoamericanas. En los años setenta, los gobiernos latinoamericanos intentaron luchar contra la influencia creciente de este instrumento poderoso y surgieron las grandes cadenas de televisión latinoamericanas, por ejemplo, Televisa de México y Globo de Brasil. En la década de 1980, aunque la televisión latinoamericana estaba activa en la producción de telenovelas y programas latinos de cosecha propia, la importación de las producciones estadounidenses continuaba (Fox, 1988). En otras palabras, durante esos años los Estados Unidos intentaba obtener el apoyo de la audiencia latinoamericana para sus políticas y usaba estos medios de comunicación para realizar sus objetivos hegemónicos. Hoy en día, el desarrollo de los medios de comunicación ha creado una nueva ola de hegemonía cultural. Las grandes corporaciones de medios estadounidenses no solo alientan las estaciones latinoamericanas para que trabajen con las corporaciones globales, sino también difunden el contenido producido en los Estados Unidos para la audiencia latinoamericana a través de las señales de cable y satélite proyectadas por sus canales (Sinclair 2004). CBS, MTV, CNN de Ted Turner, HBO Olé de TimeWarner Sony, Fox Latin America de Rupert Murdoch, TeleUNO de Spelling 
Entertainment, Grupo Abril de Brasil, Multivisión de México y Grupo Clarín de Argentina Clarín y Sky Latin America son los ejemplos de esta agenda hegemónica. Otro instrumento poderoso de la hegemonía cultural estadounidense es la diplomacia pública de Estados Unidos en América Latina. Los programas como la Comisión Fulbright han fomentado el intercambio académico entre los Estados Unidos y los países como Brasil, Argentina, Chile, Colombia, etc. Claramente, el Programa Fulbright como el símbolo de la diplomacia de Gobierno a Gente (Government-to-People) ha tenido una gran contribución al establecimiento de la cultura de los Estados Unidos en los países de América Latina. De hecho, aunque los medios de comunicación y los agentes culturales de América Latina continúan su lucha contra el Coloso del Norte en el ámbito mediático cada vez más globalizado, los Estados Unidos promociona sus valores liberales fortaleciendo sus planes culturales en las Américas. Cabe mencionar que en el siglo XX estos valores fueron establecidos principalmente por los dictadores impuestos por los EE.UU. Tal como argumentó Cain, los dictadores latinoamericanos respaldaron los intereses de los Estados Unidos en América Latina a cambio de las ayudas generosas que a su vez incrementaron la dependencia latinoamericana al vecino norteamericano. Estos dictadores enriquecieron los norteamericanos mientras que empobrecieron los latinoamericanos (Cain 2016). Por lo tanto, ellos allanaron el terreno para difundir los valores estadounidenses que recientemente se han representado en la forma del respeto a los derechos humanos y la democracia para perpetuar las intervenciones militares y económicas estadounidenses en los asuntos latinoamericanos.

Los principales argumentos con respecto a las capacidades militares y económicas se refieren a la América Latina subdesarrollada bajo los estándares neoliberales y estados latinoamericanos no democráticos e involucrados en conflictos. El primer argumento está relacionado con las situaciones económicas resultantes históricamente de las ambiciones de los EE.UU. en la región. El ejemplo sobresaliente de estas ambiciones económicas es el Consenso de Washington. David Slater (2004) cree que el proyecto neoliberal en América Latina ha protegido la riqueza de los Estados Unidos mediante la importación de materias primas del Sur y la exportación de productos terminados del Norte, lo que confirma también el argumento de la escuela estructuralista latinoamericana. Además, el proyecto neoliberal ha tratado de eliminar la oposición política (por ejemplo, Fidel Castro en Cuba) o la campaña de guerrilla posmoderna (por ejemplo, los zapatistas en México). Es importante destacar que los países del Tercer Mundo están subdesarrollados solo porque el desarrollo está 
definido por los estándares neoliberales (Slater 2004). Por lo tanto, las recomendaciones neoliberales para los problemas económicos de América Latina, como el Consenso de Washington, solo han complicado las dificultades latinoamericanas. Entonces, América Latina en efecto necesita las alternativas económicas para sus problemas. El segundo argumento está relacionado con las políticas militares de los Estados Unidos, los dictadores impuestos según sus intereses en la región y los problemas del narcotráfico. Los países latinoamericanos son anti-democráticos porque tienen un ámbito favorable para las actividades militares debido a la presencia de los bases militares estadounidenses y las operaciones militares de los EE.UU. en los países de la región y porque los gobernantes latinoamericanos han sido dictadores quienes violan los derechos humanos, pero irónicamente durante la Guerra Fría la mayoría de estos dictadores fueron los aliados y amigos de los EE.UU. en América Latina. Cabe mencionar que en las décadas recientes la propaganda de los medios estadounidenses introduce a los presidentes democráticamente elegidos como dictadores porque estos presidentes oponen las intervenciones de los EE.UU. en sus asuntos domésticos. Además, los países de América Latina se consideran involucrados en los conflictos debido al tráfico de drogas y las actividades narcóticos. Es importante destacar que el aspecto militar de estos conflictos deriva de las políticas anti-narcóticas estadounidenses. Por ejemplo, uno de los planes de los EE.UU. para erradicar narcoterrorismo fue la Guerra contra las Drogas pero según Egan esa Guerra ha causado otros problemas peligrosos. La militarización de los departamentos de policía y el creciente nivel de las agresiones y violencias de estos departamentos en situaciones que no están relacionadas con las drogas ilegales se encuentran entre los problemas más peligrosos causados por la Guerra contra las Drogas (Egan 1999). Por lo tanto, la Guerra contra las Drogas no solo no ha erradicado el tráfico de drogas, sino también ha tenido un efecto negativo en las decisiones económicas y políticas de los países de origen de las drogas. En resumen, las capacidades económicas y militares de los EE.UU. que a su vez derivan de sus ambiciones en las Américas, aun justifican las intervenciones actuales de los EE.UU. en los asuntos domésticos de los países latinoamericanos.

Las organizaciones liberales son el principal pilar del enfoque hegemónico de los Estados Unidos hacia la región. Las principales organizaciones multilaterales en las Américas incluyen la Unión Panamericana y su sucesora la Organización de los Estados Americanos (OEA). Desde los primeros años de las relaciones entre EE.UU. e América Latina, estas organizaciones se han dedicado a aumentar el poder, el rol y la influencia de los EE.UU. Los países latinoamericanos se han 
hecho miembro de estas organizaciones, deseando tener las ventajas de una relación más estrecha con los Estados Unidos a fin de resolver sus problemas en un contexto interamericano. Pero estas instituciones actúan a base de las asimetrías del poder. Es decir, aunque Estados Unidos se limita debido a su afiliación a tales organizaciones, pero estas organizaciones no tienen la misma importancia de sus intereses. Por lo tanto, Estados Unidos usa estas instituciones para desarrollar sus propios intereses y lograr sus propios objetivos. Además, cuando sus intereses son verdaderamente vitales, emplea otros métodos para desarrollarlos. Claramente, el comportamiento de los EE.UU. en las organizaciones más jóvenes como la Cumbre de las Américas no parece diferir mucho del modelo de la OEA. En suma, las asimetrías de poder y el comportamiento hegemónico definen el rol de los Estados Unidos en las instituciones multilaterales interamericanas.

Las tres categorías que fueron mencionadas resumen el proceso del surgimiento y mantenimiento del bloque hegemónico de los EE.UU. en las Américas (Figura 4). Ese círculo hegemónico confirma que la política exterior de los Estados Unidos hacia sus vecinos latinoamericanos siempre se ha basado en su excepcionalismo.

Figura 4. El momento dialéctico de la hegemonía estadounidense en las Américas

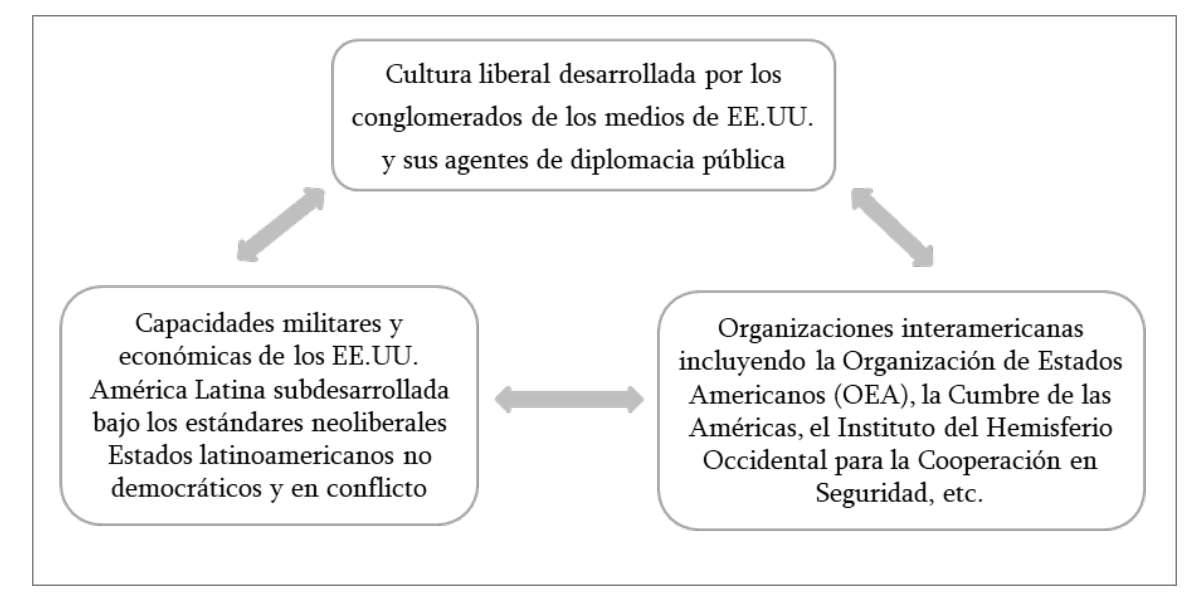

Fuente: Autor. 


\section{CONCLUSIÓN}

Esta investigación ofreció una investigación histórica sobre el proceso de la formación de la hegemonía estadounidense en América Latina. Según la perspectiva neo-Gramsciana, la hegemonía dentro de una estructura histórica se constituye en tres esferas de actividad: las "relaciones sociales de producción" que abarcan la totalidad de las relaciones sociales en formas materiales, institucionales y discursivas que producen fuerzas sociales particulares; "Formas de estado" que incluyen complejos históricamente contingentes de la sociedad civil-estatal; y "Órdenes mundiales" que no solo muestran las fases de estabilidad y conflicto, sino también explican cómo podrían surgir las formas alternativas del orden mundial. Entonces, EE.UU. ha construido su bloque hegemónico basándose en los valores liberales que también se consideran como una medida para mantener su hegemonía.

El surgimiento de los Estados Unidos como hegemón en las Américas se remonta a los primeros años de la formación de los Estados Unidos. La creencia en la inferioridad latinoamericana formó el núcleo esencial de las relaciones interamericanas que se reflejó en la intervención cultural, militar, económica y política de los EE.UU. en los asuntos domésticos de los países latinoamericanos. Asimismo, el Panamericanismo, como la realización ideológica de esta mentalidad, fue promovido por las instituciones interamericanas que allanaron el terreno para desarrollar las ambiciones de los EE.UU. bajo las políticas exteriores como Gran Garrote, Diplomacia del Dólar, Buena Vecindad, Alianza para el Progreso, fomento de la democracia, Lucha contra Droga, etc. Generalmente, la mentalidad colonial estadounidense constituye la base de su proyecto liberal en sus vecinos latinoamericanos y la hegemonía liberal de los EE.UU. ha usado la coerción y el consenso para establecer su posición dominante en el hemisferio occidental. En este sentido, la investigación histórica de las relaciones entre los Estados Unidos y América Latina muestra que la hegemonía liberal de los Estados Unidos en América Latina es preservada y promovida por tres pilares: Cultura liberal desarrollada por los conglomerados de los medios de EE.UU. y sus agentes de la diplomacia pública; Organizaciones interamericanas incluyendo la Organización de Estados Americanos (OEA), la Cumbre de las Américas, el Instituto del Hemisferio Occidental para la Cooperación en Seguridad, etc.; y Capacidades militares y económicas de los EE.UU. que se reflejan en la América Latina subdesarrollada bajo los estándares neoliberales y los estados latinoamericanos no democráticos y en conflicto. 
Finalmente, el círculo vicioso del bloque hegemónico de los Estados Unidos confirma que la política exterior de los Estados Unidos hacia sus vecinos latinoamericanos siempre se ha basado en su excepcionalismo. Desde el principio, el Norte superior y el Sur inferior han sido el elemento crucial de las interacciones interamericanas. Además, como señala Brian Loveman, América Latina siempre ha servido a los intereses de los Estados Unidos. A pesar de la falta de respeto y desprecio por la región y sus pueblos, Estados Unidos intentó "construir y consolidar un bastión" en América para realizar su proyecto global. De hecho, la América Latina ha sido un laboratorio de las políticas exteriores que se exportaron a otras partes del mundo (Loveman 2010). Por lo tanto, los países latinoamericanos han sido el terreno de prueba de la hegemonía global de los Estados Unidos y los tres pilares de su bloque liberal se han extendido a otras partes del mundo. Cabe mencionar que los tres pilares del bloque liberal de los EE.UU. han creado un ciclo fuerte que la única manera de desafiarlo es ofrecer una alternativa al orden liberal. Mientras que el Latinoamericanismo busca ofrecer esta alternativa, las evoluciones internacionales también están definiendo nuevos desafíos que deben ser examinados cuidadosamente.

\section{REFERENCIAS}

Bieler, A., \& Morton, A. D. (2004). A Critical Theory Route to Hegemony, World Order and Historical Change: Neo-Gramscian Perspectives in International Relations. Capital and Class, 81(1), 85-113.

Brewer, S. (2006). Borders and Bridges: A History of U.S.-Latin American Relations. Connecticut: Praeger Security International.

Cain, C. (2016). Cuba Evokes the History of American Imperialism in Latin America. CounterPunch. Retrieved September 26, 2016, from https://www.counterpunch.org/2016/03/23/cuba-evokes-the-history-ofamerican-imperialism-in-latin-america/

Cerón, R. A. (2002). Los nuevos sujetos del derecho internacional. Quito: Ediciones Abya-Yala.

Cox, R. W. (1981). Social Forces, States and World Orders: Beyond International Relations Theory. Millennium: Journal of International Studies, 10(2), 126155.

Cox, R. W. (1983). Gramsci, Hegemony and International Relations: An Essay in Method. Millennium: Journal of International Studies, 12(2), 162-175. 
Cox, R. W. (1987). Production, Power and World Order: Social Forces in the Making of History. New York: Columbia University Press.

Deudney, D., \& Ikenberry, J. (1999). The Nature and Sources of Liberal International Order. Review of International Studies, 25(2), 179-196.

Egan, T. (1999). Soldiers of the Drug War Remain on Duty. New York Times. Retrieved April 23, 2016, from https://www.nytimes.com/1999/03/01/us/soldiers-of-the-drug-war-remainon-duty.html

Fontana, B. (2008). Hegemony and Power in Gramsci. In R. Howson \& K. Smith (Eds.), Hegemony. Studies in Consensus and Coercion. New York: Routledge.

Fox, E. (1988). Media and Politics in Latin Americ. London: Sage Publications.

Gardner, P. (2006). Historical Analysis. In V. Jupp (Ed.), The Sage Dictionary of Social Research Methods (pp. 134-136). Thousand Oaks, CA: SAGE Publications.

Gilderhus, M. T. (2000). The Second Century: U.S.--Latin American Relations Since 1889. Wilmington, DE: Scholarly Resources.

Gobat, M. (2013). The Invention of Latin America: A Transnational History of Anti-Imperialism, Democracy, and Race. American Historical Association, 118(5), 1345-1375.

Gramsci, A. (1949a). Opere di Antonio Gramsci (1947-72) (Vol. 3: Gli intellettuali e l'organizzazione della cultura). Turino: Einaudi.

Gramsci, A. (1949b). Opere di Antonio Gramsci (1947-72) (Vol. 2: Il materialismo storico e la filosofia di Benedetto Croce). Turino: Einaudi.

Gramsci, A. (1949c). Opere di Antonio Gramsci (1947-1972) (Vol. 4: Il Risorgimento). Turino: Einaudi.

Gramsci, A. (1951). Opere di Antonio Gramsci (1947-72) (Vol. 7: Passato e presente). Turino: Einaudi.

Hakim, P. (2006). Is Washington Losing Latin America? Foreign Affairs, 85(1), 39-53.

Howson, R., \& Smith, K. (2008). Hegemony and the Operation of Consensus and Coercion. In R. Howson \& K. Smith (Eds.), Hegemony. Studies in Consensus and Coercion. New York: Routledge.

Joseph, J. (2002). Hegemony: A Realist Analysis. London/New York: Routledge. 
Kant, I. (1970). Perpetual peace: A philosophical sketch. In H. Reiss (Ed.), Kant's Political Writings: Edited with an Introduction and Notes by Hans Reiss (pp. 93-130). Cambridge: Cambridge University Press.

Keohane, R. O. (1984). After Hegemony: Cooperation and Discord in the World Political Economy. Princeton: Princeton University Press.

Lavrakas, P. J. (2008). Encyclopedia of Survey Research Methods. Thousand Oaks, CA: SAGE Publications.

Lundy, K. S. (2008). Historical research. In L. M. Given (Ed.), The SAGE Encyclopedia of Qualitative Research Methods (pp. 395-399). Thousand Oaks, CA: SAGE Publications.

Nye, J. S. (2002). Limits of American Power. Political Science Quarterly, 1174), 545-559.

O'Brien, T. F. (2007). Making the Americas: The United States and Latin America from the Age of Revolutions to the Era of Globalization. Albuquerque: University of New Mexico Press.

Rangel, C. (1981). Mexico and other dominoes. Commentary Magazine, 29-33.

Ransome, P. (1992). Antonio Gramsci: A New Introduction. New York: Harvester/Wheatsheaf.

Schoultz, L. (1998). Beneath the United States: A History of U.S. Policy toward Latin America. Cambridge, Massachusetts: Harvard University Press.

Sinclair, J. (2004). Geolinguistic Region as Global Space: The Case of Latin America. In R. Allen \& A. Hill (Eds.), The Television Studies Reader. London: Routledge.

Singh, Y. K. (2006). Fundamental of Research Methodology and Statistics. New Delhi: New Age International.

Slater, D. (2004). Geopolitics and the Post-Colonial: Rethinking North-South Relations. Malden, MA: Blackwell Publishing.

Smith, J. (2005). The United States and Latin America: A history of American diplomacy, 1776-2000. New York: Routledge.

Tulchin, J. S. (2016). Latin America in International Politics: Challenging US Hegemony. Boulder: Lynne Rienner Publishers.

Wade, R. (2014). Growth, Inequality, and Poverty: Evidence, Arguments, and Economists. In J. Ravenhill (Ed.), Global Political Economy. Oxford: Oxford University Press. 
Webb, M. C., \& Krasner, S. D. (1989). Hegemonic Stability Theory: An Empirical Assessment. Review of International Studies, 15(2), 183-198.

Recibido: 5 de noviembre de 2019

Aceptado: 13 de diciembre de 2019

Elaheh Nourigholamizadeh tiene un doctorado en Estudios Norteamericanos de la Facultad de Estudios del Mundo, Universidad de Teherán, Irán, con excelencia académica. También recibió su maestría en Estudios Latinoamericanos de la Universidad de Teherán con excelencia académica. Sus áreas de interés incluyen la política y economía de América Latina y las relaciones entre Estados Unidos y América Latina. Sus otras actividades de investigación están relacionadas con la historia, cultura y sociedad de América Latina. Dra. Nourigholamizadeh ha impartido cursos sobre la política y economía de América Latina en la Universidad de Teherán y ha colaborado con numerosas universidades y centros de investigación dentro y fuera de Irán. Actualmente se encuentra en una estancia de investigación en la Universidad Autónoma de Madrid, Facultad de Filosofía y Letras. 